\section{Technical Brief}

\section{Lateral Flow Devices to Rapidly Determine Levels of Stable Botrytis Antigens in Table and Dessert Wines}

\author{
Frances M. Dewey, ${ }^{1} *$ Christopher C. Steel, ${ }^{2}$ and Sarah J. Gurr ${ }^{3}$
}

${ }^{1}$ Research Associate, ${ }^{3}$ Professor, Plant Sciences, University of Oxford, South Parks Rd., Oxford, OX1 3RB, UK; and ${ }^{2}$ Professor, National Wine and Grape Industry Centre, School of Agricultural and Wine Sciences, Charles Sturt University, Locked Bag 588, Wagga Wagga, NSW 2678, Australia.

*Corresponding author (email: molly @ffmdewey.com)

Acknowledgments: This research was supported by a Senior Fellowship award to Prof Chris Steel from the British Society of Plant Pathology. The authors also thank Ms. C.E. Hofmann for collating the collection of dessert wines used in this study. The hybridoma cell line secreting the Botrytis monoclonal antibody, BC-12.C A4, employed in the Lateral Flow devices, is the property of Oxford University and is used under licence from the University by Forsite Pocket Diagnostics, UK, and EnviroLogix, US. Some royalties go to author F.M. Dewey.

Manuscript submitted Aug 2012, revised Dec 2012, accepted Dec 2012

Copyright (C) 2012 by the American Society for Enology and Viticulture. All rights reserved.

Abstract: Two commercially available Botrytis Lateral Flow Devices (B-LFDs) (immunochromatographic devices), one from EnviroLogix, Maine, USA the other from Forsite Diagnostics, York, UK were tested and compared for their ability to detect and quantify levels of a highly stable Botrytis antigen in table wines and dessert wines. Table wines were diluted 1:40 and dessert wines 1:500 in phosphate buffered saline plus Tween $20(0.05 \% \mathrm{v} / \mathrm{v})(\mathrm{PBST})$. Results from both types of devices were comparable and repeatability was good. This study shows that Botrytis Lateral Flow Devices could provide a useful tool for wine makers interested in relating levels of Botrytis antigens in table and dessert wines to sensory properties.

Key words: antigens, Botrytis, grey mould, Lateral Flow devices, noble rot, table and dessert wines 


\section{Introduction}

It is well recognized that Botrytis cinerea is the main cause of bunch rot of grape berries in

temperate climates (Marois et al. 1993, Slomczynski et al. 1995). Bunch rot is undesirable for production of table wines because it is associated with off-flavours and unpleasant aromas in finished wines and loss of colour in red wines. In contrast, the presence of $B$. cinerea infections in late harvest grape berries is desirable because Botrytis is believed to be responsible for the desirable aromas and flavours (Sarrazin et al. 2007, Sivertsen et al. 2005). However, in both cases, any study of the relationship between levels of Botrytis in wines and sensory properties of wines is difficult because there has been no easy way to measure levels of Botrytis antigens in finished wines. The use of rapid, user-friendly, immunodiagnostic Lateral-Flow Devices offers an easy method to detect fungal antigens (Dewey et al. 2008). The advantages of LFDs over other immunological methods, such as microtitre plate ELISAs (Dewey et al. 2000; Dewey 2002), and molecular tests are that they are rapid, (5-15min), can be easily operated by untrained workers and do not require laboratory facilities.

Two commercially available B-LFDs have been developed for the detection and quantification of soluble stable Botrytis-antigens, one produced by EnviroLogix, Portland, ME, USA and the other by Forsite Pocket Diagnostics, York, UK. Although both employ the same Botrytis monoclonal antibody, BC-12.CA4 (Meyer and Dewey 2000), that recognizes a constitutively produced, thermostable antigen, that is not metabolized during fermentation, there are technical differences and the performance of both tests has never been compared.

The format used by both devices is a sandwich assay in which the antigens are captured by the Botrytis antibody which is bound, in the EnviroLogix test to gold nanoparticles and, in the Pocket Diagnostics test to 'latex' particles. The bound conjugates are present in an absorbent pad overlaying a 
nitrocellulose membrane (Fig 1). When the test liquid is applied, the particles move along the membrane by capillary action; those carrying the Botrytis antigens are arrested at the test line on the membrane by a pre-printed line of Botrytis-antibodies. In the EnviroLogix test, the positive test line appears pink because the antibody is bound to gold particles whereas the positive test line in the Forsite Pocket Diagnostics devices appears blue because the latex-antibody conjugate is blue. Those particles to which no antigen is bound continue to move forward along the membrane and, in the case of the EnviroLogix test they are arrested at the control line, by a pre-printed line of anti-mouse antibodies, to give a second pink line. The control line in the Pocket Diagnostics test is formed in a different way. Blue latex particles, coated with non-specific rabbit-antibodies, are mixed with the murine Botrytis-bound latex particles in the absorbent starting pad and these, which are not arrested at the test line, are arrested at the control line by a line of anti-rabbit antibodies (Fig. 2). The differences between the two types of LFDs, apart from colour of the test and control bands, could be significant. The control line in the EnviroLogix tests is dependent on there being an excess of Botrytis gold-conjugates particles binding at the control line whereas the Pocket Diagnostics control line is not dependent on an excess of Botrytis antibody coated latex particles. These technical differences mean that, if excess antigen is present, there could be significant differences in the intensity of the control bands because the SI value is the percentage of the reflectivity of the background minus that of the test line divided by the reflectivity of the background minus that of the control line. The reflectivities of the test lines, control lines and backgrounds are measured with their respective custommade scanners (reflectometers). The percentage of the reflectivity of the background minus that of the test line divided by the reflectivity of the control line is automatically expressed by the scanners as the Signal Intensity (SI).

The aims of this study were to compare two commercially available B-LFDs for the quantification of Botrytis antigens in a range of red and white table wines and dessert wines. 
Wines. All wines tested were purchased either in the UK or Australia or, in the case of the reference dessert wine Dolce, from Far Niente, California, USA. Details of grape varietal and vintage of the wines

are given for red wines in Table 1, white wines in Table 2, dessert wines in Table 3. All wines were stored and tested at room temperature, precipitates were not seen in any of the red wines.

Lateral Flow Devices. B-LFD kits and their respective scanners were purchased from EnviroLogix (kit batch number 151208) (Portland, ME, USA) and from Forsite Pocket Diagnostics (kit batch number Y01 for table wines and AA01 for desert wines) (York, UK). The two different batches of Forsite Pocket Diagnostic kits differed in that AA01 had a higher concentration of the Botrytis antibody conjugated particles in the test pad than Y01. Unless otherwise stated, all wines were diluted into phosphate buffered saline + Tween $20(0.05 \% \mathrm{v} / \mathrm{v})(\mathrm{PBST})$, table wines were diluted 1:40, dessert wines 1:500. Tests with the EnviroLogix B-LFDs were done by placing the absorbent pad of the device in $400 \mu 1$ of diluted wine for $10 \mathrm{~min}$; the absorbent pad was then removed and the device was inserted into the EnviroLogix reader (scanner) to determine the SI value. For the Forsite Pocket Diagnostics tests, $70 \mu \mathrm{l}$ of the diluent were pipetted into the well of the device and, after $10 \mathrm{~min}$, the devices were inserted into the Forsite reader and the SI value recorded. On completion the SI values of the EnviroLogix tests remained stable because the absorbent start pad is removed before the SI values are determined but the SI values of the Pocket Diagnostics tests tend to increase with time because the start pad is not removed. Therefore, care was taken to time the tests and determine the SI values in both cases after $10 \mathrm{~min}$.

To determine repeatability of the devices and threshold detection levels a dilution series of the reference dessert wine Dolce (Far Niente, CA, USA, 1998 vintage), used in previous studies (Dewey et al. 2008) was tested. 


\section{Results and Discussion}

Standards and Repeatability In tests, done with both devices, on a series of dilutions of the reference dessert wine, Dolce, correlation was good, $\mathrm{R}^{2}$ 0.939, (Fig 3). The problem of repeatability was addressed in a previous publication by Dewey et al, (2008) where tests were done in triplicate on a dilution series of the dessert wine Dolce. There was little variation between replicates and so for this reason, and to reduce total costs of the project, tests on each of the experimental table and dessert wines were only done once. The threshold detections levels were similar. Both devices could detect down to 0.0125\% standard in PBST but there were differences in the numerical value of the signals from the control or buffer alone, SI values for the EnviroLogix devices were zero, but for the Forsite devices they ranged from 0 to 6 (batch Y01) and from 18.6 to 20 (batch AA01).

Table wines. SI values from the tests done on 36 red and 32 white table wines and 27 dessert wines are given in Tables 1, 2, and 3, respectively. In all cases, there was good correlation between the SI values form the EnviroLogix B-LFDs and the Forsite Pocket Diagnostics B-LFDs (Figs. 4A, B and C For red wines, the $\mathrm{R}^{2}$ value was 0.867 for white wines 0.7456 and 0.849 for dessert wines. The SI values from tests on red wines by the EnviroLogix B-LFDs ranged from 0 to 48 and from 3.3 to 36 by the Forsite Diagnostics B-LFDs. In tests on white wines, SI values ranged from 0 to 44 with the EnviroLogix BLFDs and from 3.3 to 36 with the Forsite Pocket Diagnostics LFDs. The range in SI values from tests with the EnvioLogix B-LFDs was greater than those with the Forsite Pocket Diagnostics LFDs; this, in the case of the high-end results, probably reflects the difference in the capture antibodies used for the control lines. At high concentrations of antigen, the Botrytis binding sites on the antibody-coated particles in the test pad of both devices become saturated. This does not affect the intensity of the control line in the Forsite devices because the formation of the control line is independent of the level of antigen 
binding. But, in the EnviroLogix devices the control line is dependent upon there being an excess of free, unbound Botrytis antibody-coated nanogold particles. Therefore, when there are fewer Botrytis-free antibody bound particles available to travel to the control line the intensity of the control line is lower. In both cases, because the SI value is calculated from the percentage difference between the reflectance of the background minus the test line divided by the reflectance of the background minus the control line, a weaker control line would give higher SI values.

Dessert wines. The SI values using the Forsite B-LFD (batch AA01) were much higher than those from Envirologix B-LFDs. Although the values were higher (15 to 134) they correlated well with the SI values from the EnviroLogix B-LFDs (0-50) giving an $\mathrm{R}^{2}$ value of 0.849 (Fig. 4C).

Applications. Both devices are simple and easy to use. The Forsite Pocket Diagnostics devices and their custom made reader (scanner) are designed to be used in the field. Their devices, which are encased in plastic, are more robust but more expensive.

Pilot studies, not reported here, have shown that the level of Botrytis-antigens in grape juice remains constant throughout fermentation irrespective of grape varietal. These devices should therefore, provide useful tools for relating levels of Botrytis antigens to the sensory properties of wines such as taste and aroma and could also be of particular value for sparkling wine production where proteases produced by Botrytis are known to affect the formation and retention of bubbles (Marchal et al. 2001, Cilindre et al. 2007).

We did not attempt to relate the SI values from tests on finished wines to levels of rot in the vineyard. Previous studies have shown that the Botrytis-SI values correlate well with tests on juice from hand-picked, hand-sorted, berries but not with visual estimates of machine-picked grapes (Dewey et al. 2008). In the latter, heavily-infected berries are often not counted because they are easily squashed 
139

during transit. On-site field estimates of rot are also problematic because they are totally dependent on the method of sampling and the variations found within different climatic regions in vineyards. We found that, in tests with juices, diluted 1:40 in PBST, from hand-picked, hand-sorted grape berries (Chardonnay) with $0.6,1.3,2.5,5.0$ and $10.0 \%$ Botrytis- rot (determined on the basis of incidence, not weight) that SI values with the EnviroLogix B-LFDs were 10.5, 16.7, 26.2, 34.6 and 39.7 respectively (Dewey et al., 2008). Thus, B-LFD tests on red and white table wines with SI values greater than 35 indicate that the wines were made from grape berries with 5\% or more average level of Botrytis rot. However, the value of the Botrytis LFDs is not in determining estimates of rot in the field but in providing a means of measuring the levels of Botrytis antigens throughout the fermentation process and in finished wines.

\section{Conclusions}

Both the EnviroLogix and the Forsite Pocket Diagnostics Botrytis LFDs are useful tools for rapidly determining levels of Botrytis antigens in wines. They provide an easy mechanism for wine makers interested in studying the relationship between of the levels of Botrytis antigens and the aroma and flavours of wines. Results from both devices were comparable. The Forsite Pocket Diagnostics B-LFDs and their custom-made reader are designed for field use; they are more expensive than the EnviroLogix B-LFDs but, because they are housed in plastic they have the advantage of being more robust.

\section{Literature Cited}

Cilindre, C., A.J. Castro, C. Clement, P. Jeandet, and R. Marchal. 2007. Food Chemistry 103:139-149.

Dewey, F.M., S.E. Ebeler, D.O. Adams, A.C. Noble, and U.M. Meyer. 2000. Quantification of Botrytis in grape juice determined by a monoclonal antibody-based immunoassay. American Journal of Viticulture and Enology 51:276-282.

Dewey, F.M. 2002. Botrytis antigens in wine. The Australian and New Zealand Grapegrower and Winemaker, March issue, 20-21. 
162

163

164

165

166

167

168

169

170

171

172

173

174

175

176

177

178

Dewey, F.M., M. Hill, And R. De Scenzo. 2008. Quantification of Botrytis and Laccase in Wine grapes. American Journal of Enology and Viticulture 59: 47-54.

Marchal, R., I. Tabary, M. Valade, D. Moncomble, L. Viaux, B. Robillard, and P. Jeandet. 2001 Effects of Botrytis cinerea infection on Champagne wine foaming properties. Journal of Science Food and Agriculture 10: 1371-20001.

Marois, J.J, A.M. Bledsoe, R.W. Ricker, and R.M. Bostock. 1993. Sampling for Botrytis cinerea in harvested grape berries. American Journal of Enology and Viticulture 44: 261-265.

Meyer, U. and F.M. Dewey. 2000. Efficacy of different immunogens for raising monoclonal antiobides to Botrytis cinerea. Mycological Research 104: 979-987.

Sarrazin, E., D. Dubourdieu, and P. Darriet. 2007. Characterization of key-aroma compounds of botrytized wines, influence of grape botrytization. Food Chemistry 103: 536-545.

Slomczynski, D., J.P. Nakas, and S.W.Tanenbaum. 1995. Production and characterisation of laccase from Botrytis cinerea. Applied Environmental Microbiology 61: 907-912.

Sivertsen, H.K.,F.M. Dewey, and H. Heymann. 2005. Relationship between sensory descriptive analysis and levels of Botrytis antigens in dessert wines. American Journal of Enology and Viticulture 56: 330335. 
American Journal of Enology and Viticulture (AJEV). doi: 10.5344/ajev.2012.12103

AJEV Papers in Press are peer-reviewed, accepted articles that have not yet been published in a print issue of the journal or edited or formatted, but may be cited by DOI. The final version may contain substantive or nonsubstantive changes.

Table 1 Red wines tested for levels of Botrytis antigens by EnviroLogix (EL) and Forsite Pocket Diagnostics (FPD) Botrytis Lateral Flow devices. SI = signal intensity. Wines were diluted 1/40 in PBST prior to analysis. Each wine was only tested once.

\begin{tabular}{|c|c|c|c|c|}
\hline Variety & Origin & Vintage & SI EL & SI FPD \\
\hline Barbera & Italy & 2007 & 27 & 18.1 \\
\hline Cab Sauv & Australia & 2006 & 0 & 5.2 \\
\hline Cab Sauv & Australia & 2009 & 0 & 4.8 \\
\hline Cab Sauv / Merlot & Australia & 2008 & 0 & 6.3 \\
\hline Cab Sauv / Merlot & Chile & 2009 & 5 & 5.9 \\
\hline Cab Sauv / Merlot & France & 2005 & 10 & 6.3 \\
\hline Carmenere & Chile & Unknown & 9 & 6.8 \\
\hline Grenache / Tempranillo & Spain & 2009 & 18 & 10.3 \\
\hline Malbec & Argentina & 2008 & 5 & 5.6 \\
\hline Malbec & Argentina & Unknown & 14 & 9.1 \\
\hline Merlot & Chile & 2009 & 7 & 3.3 \\
\hline Merlot / Cab Sauv & France & 2007 & 28 & 15.3 \\
\hline Monastrell & Spain & 2003 & 18 & 10.6 \\
\hline Monastrell & Spain & 2005 & 37 & 18.5 \\
\hline Pinot noir & Argentina & 2008 & 40 & 24.3 \\
\hline Pinot noir & Australia & 2005 & 23 & 13.4 \\
\hline Pinot noir & Australia & 2008 & 0 & 5.2 \\
\hline Pinot noir & Australia & 2006 & 0 & 6.6 \\
\hline Rioja & Spain & 2003 & 32 & 20.6 \\
\hline Rioja & Spain & 2005 & 35 & 19 \\
\hline Rioja & Spain & 2007 & 35 & 16.6 \\
\hline Rioja & Spain & 2008 & 36 & 17.6 \\
\hline Shiraz & Australia & 2008 & 0 & 3.4 \\
\hline Shiraz & Australia & 2009 & 4 & 4.9 \\
\hline Syrah & France & 2007 & 30 & 17.9 \\
\hline Unknown & France -Beaujolais & 2007 & 35 & 15.9 \\
\hline Unknown & France -Bordeaux & 1988 & 10 & 6.8 \\
\hline Unknown & France -Bordeaux & 1988 & 48 & 35.5 \\
\hline Unknown & France -Bordeaux & 1998 & 48 & 34.3 \\
\hline Unknown & France -Bordeaux & 2005 & 5 & 3.2 \\
\hline Unknown & France -Bordeaux & 2007 & 29 & 17 \\
\hline Unknown & France -Cotes du Rhone & 2001 & 8 & 6.9 \\
\hline Unknown & Italy -Chianti & 1998 & 38 & 20.1 \\
\hline Unknown & Italy -Chianti & 2006 & 22 & 10.8 \\
\hline Unknown & Portugal -Alentejo & 2008 & 5 & 6.2 \\
\hline Unknown & Spain -Madeira & 1981 & 29 & 11.3 \\
\hline
\end{tabular}

Cab Sauv $=$ Cabernet Sauvignon. 
American Journal of Enology and Viticulture (AJEV). doi: 10.5344/ajev.2012.12103

AJEV Papers in Press are peer-reviewed, accepted articles that have not yet been published in a print issue of the journal or edited or formatted, but may be cited by DOI. The final version may contain substantive or nonsubstantive changes.

Table 2 White wines tested for levels of Botrytis antigens by EnviroLogix (EL) and Forsite Pocket Diagnostics (FPD) Botrytis Lateral Flow devices. SI = signal intensity. Wines were diluted $1 / 40$ in PBST prior to analysis. Each wine was only tested once.

\begin{tabular}{|c|c|c|c|c|}
\hline Variety & Origin & Vintage & SI EL & SI FPD \\
\hline Chardonnay & Australia & 2007 & 13 & 7.2 \\
\hline Chardonnay & Australia & 2008 & 0 & 3.5 \\
\hline Chardonnay & Australia & 2008 & 7 & 7.8 \\
\hline Chardonnay & Australia & 2009 & 0 & 7.1 \\
\hline Chardonnay & Australia & 2009 & 0 & 4.0 \\
\hline Chardonnay & Australia & 2008 & 4 & 10.0 \\
\hline Chardonnay & Chile & 2009 & 8 & 4.7 \\
\hline Chardonnay & France & 2007 & 41 & 26.6 \\
\hline Chardonnay & France & 2008 & 30 & 16.4 \\
\hline Chardonnay & France & 2008 & 44 & 28.5 \\
\hline Chardonnay & S. Africa & 2008 & 8 & 7.7 \\
\hline Chardonnay & S. Africa & 2009 & 6 & 5.5 \\
\hline Chardonnay & S. Africa & 2009 & 9 & 7.1 \\
\hline Chardonnay & Australia & 2008 & 43 & 29.2 \\
\hline Chardonnay/Viognier & France & 2009 & 0 & 14.2 \\
\hline Gewurztraminer & Chile & 2008 & 9 & 0.7 \\
\hline Muscat & France & 2008 & 29 & 8.2 \\
\hline Petit Chablis & France & 2008 & 38 & 22.4 \\
\hline Pinot Grigio & Italy & 2009 & 15 & 8.6 \\
\hline Pinot Grigio & Italy & 2009 & 16 & 7.7 \\
\hline Pinot Grigio & $\mathrm{NZ}$ & 2008 & 0 & 7.2 \\
\hline Pinot Grigio & Italy & 2009 & 11 & 9.1 \\
\hline Pouilly Fume & France & 2008 & 29 & 14.9 \\
\hline Riesling & Australia & 2008 & 2 & 5.6 \\
\hline Riesling & Germany & 2007 & 32 & 18.7 \\
\hline Riesling & Germany & 2007 & 28 & 20.4 \\
\hline Riesling & $N Z$ & 2008 & 34 & 23.4 \\
\hline Sancerre & French & 2007 & 29 & 14.0 \\
\hline Sauvignon Blanc & Chile & 2009 & 16 & 6.7 \\
\hline Sem. / Sauv. Blanc & Australia & 2009 & 11 & 3.6 \\
\hline UWB & France & 2008 & 9 & 9.4 \\
\hline Viognier & Argentina & 2009 & 7 & 5.4 \\
\hline
\end{tabular}

UWB = Unknown white blend 
American Journal of Enology and Viticulture (AJEV). doi: 10.5344/ajev.2012.12103

AJEV Papers in Press are peer-reviewed, accepted articles that have not yet been published in a print issue of the journal or edited or formatted, but may be cited by DOI. The final version may contain substantive or nonsubstantive changes.

Table 3 Dessert wines tested for levels of Botrytis antigens by EnviroLogix (EL) and Forsite Pocket Diagnostics (FPD) Botrytis Lateral Flow devices. Wines were diluted 1/500 in PBST prior to analysis. $\mathrm{SI}=$ signal intensity. Bottle rep = bottle replicates of the same wine/vintage. Each bottle was only tested once. All wines of Australian origin were made with Semillon grapes while wines from France were made with an unknown blend of Semillon and Sauvignon Blanc.

\begin{tabular}{|c|c|c|c|c|c|}
\hline Wine & Bottle rep & Origin & Vintage & SI EL & FPD \\
\hline 1 & 1 & Australia & 1984 & 45 & 100 \\
\hline 2 & 1 & Australia & 1985 & 40 & 82 \\
\hline 3 & 1 & Australia & 1995 & 45 & 96 \\
\hline 4 & 1 & Australia & 2000 & 41 & 106 \\
\hline 5 & 1 & Australia & 2002 & 34 & 79 \\
\hline 6 & 1 & Australia & 2004 & 25 & 71 \\
\hline 6 & 2 & Australia & 2004 & 22 & 61 \\
\hline 6 & 3 & Australia & 2004 & 25 & 79 \\
\hline 6 & 4 & Australia & 2004 & 27 & 66 \\
\hline 7 & 1 & Australia & 2004 & 30 & 57 \\
\hline 7 & 2 & Australia & 2004 & 29 & 59 \\
\hline 7 & 3 & Australia & 2004 & 30 & 68 \\
\hline 8 & 1 & Australia & 2005 & 14 & 32 \\
\hline 9 & 1 & Australia & 2006 & 0 & 15 \\
\hline 9 & 2 & Australia & 2006 & 0 & 17 \\
\hline 9 & 3 & Australia & 2006 & 0 & 14 \\
\hline 10 & 1 & Australia & 2006 & 24 & 86 \\
\hline 10 & 2 & Australia & 2006 & 25 & 57 \\
\hline 10 & 3 & Australia & 2006 & 22 & 44 \\
\hline 11 & 1 & Australia & 2006 & 5 & 32 \\
\hline 11 & 2 & Australia & 2006 & 5 & 34 \\
\hline 11 & 3 & Australia & 2006 & 6 & 35 \\
\hline 12 & 1 & Australia & 2006 & 35 & 62 \\
\hline 12 & 2 & Australia & 2006 & 36 & 88 \\
\hline 12 & 3 & Australia & 2006 & 27 & 68 \\
\hline 13 & 1 & Australia & 2006 & 23 & 85 \\
\hline 13 & 2 & Australia & 2006 & 16 & 36 \\
\hline 13 & 3 & Australia & 2006 & 16 & 42 \\
\hline 13 & 4 & Australia & 2006 & 24 & 46 \\
\hline 14 & 1 & Australia & 2007 & 13 & 44 \\
\hline 14 & 2 & Australia & 2007 & 17 & 53 \\
\hline 14 & 3 & Australia & 2007 & 16 & 44 \\
\hline 15 & 1 & Australia & 2007 & 33 & 75 \\
\hline 15 & 2 & Australia & 2007 & 29 & 75 \\
\hline 15 & 3 & Australia & 2007 & 33 & 92 \\
\hline 16 & 1 & Australia & 2008 & 42 & 100 \\
\hline 16 & 2 & Australia & 2008 & 47 & 98 \\
\hline 16 & 3 & Australia & 2008 & 47 & 126 \\
\hline 17 & 1 & Australia & 2008 & 47 & 89 \\
\hline 17 & 2 & Australia & 2008 & 46 & 115 \\
\hline 18 & 1 & Australia & 2008 & 36 & 72 \\
\hline 18 & 2 & Australia & 2008 & 33 & 94 \\
\hline 18 & 3 & Australia & 2008 & 36 & 73 \\
\hline 18 & 4 & Australia & 2008 & 35 & 74 \\
\hline
\end{tabular}


AJEV Papers in Press are peer-reviewed, accepted articles that have not yet been published in a print issue of the journal or edited or formatted, but may be cited by DOI. The final version may contain substantive or nonsubstantive changes.

Table 3 continued

\begin{tabular}{cccccc}
\hline Wine & Bottle rep & Origin & Vintage & SI EL & FPD \\
\hline 19 & 1 & Australia & 2009 & 42 & 97 \\
19 & 2 & Australia & 2009 & 44 & 104 \\
19 & 3 & Australia & 2009 & 44 & 114 \\
20 & 1 & Australia & unknown & 46 & 104 \\
21 & 1 & Australia & unknown & 50 & 118 \\
22 & 1 & Australia & unknown & 49 & 134 \\
23 & 1 & Australia & unknown & 36 & 86 \\
24 & 1 & France & 2001 & 13 & 47 \\
24 & 2 & France & 2001 & 15 & 53 \\
24 & 3 & France & 2001 & 17 & 34 \\
25 & 1 & France & 2004 & 23 & 32 \\
25 & 2 & France & 2004 & 25 & 64 \\
25 & 3 & France & 2004 & 25 & 61 \\
26 & 1 & France & 2005 & 17 & 48 \\
26 & 2 & France & 2005 & 16 & 35 \\
26 & 3 & France & 2005 & 15 & 35 \\
27 & 1 & France & unknown & 18 & 61 \\
\hline
\end{tabular}

Flow of particles when diluted wine sample added to start pad

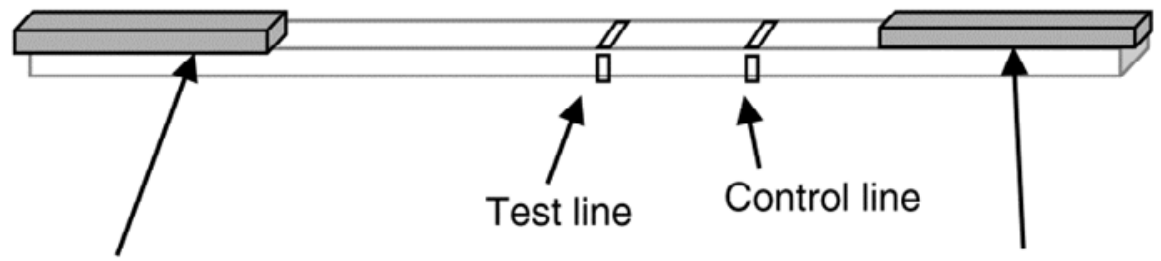

Start pad

Absorbent end pad

Figure 1 Diagram of Lateral Flow Device. The absorbent start pad in EnviroLogix devices contains Botrytis antibodies bound to nanogold particles and the control line is a pre-printed line of anti-mouse antibodies. In the Forsite Diagnostics devices the absorbent start pad contains two sets of particles one to which Botrytis antibodies are bound and the other to which non-specific rabbit antibodies are bound; the control line is composed of a pre-printed line non-specific anti-rabbit antibodies. 
American Journal of Enology and Viticulture (AJEV). doi: 10.5344/ajev.2012.12103

AJEV Papers in Press are peer-reviewed, accepted articles that have not yet been published in a print issue of the journal or edited or formatted, but may be cited by DOI. The final version may contain substantive or nonsubstantive changes.

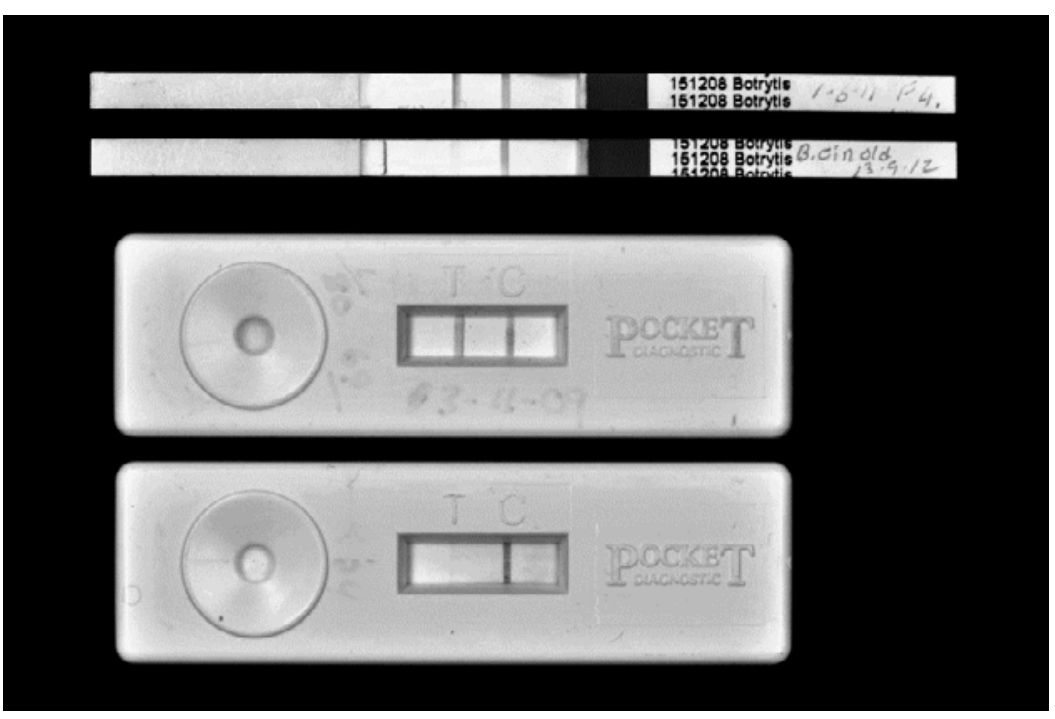

Figure 2 Completed Lateral-Flow tests, (a) EnviroLogix tests, (b) Forsite-Pocket Diagnostics tests: + positive test result, - negative test result.

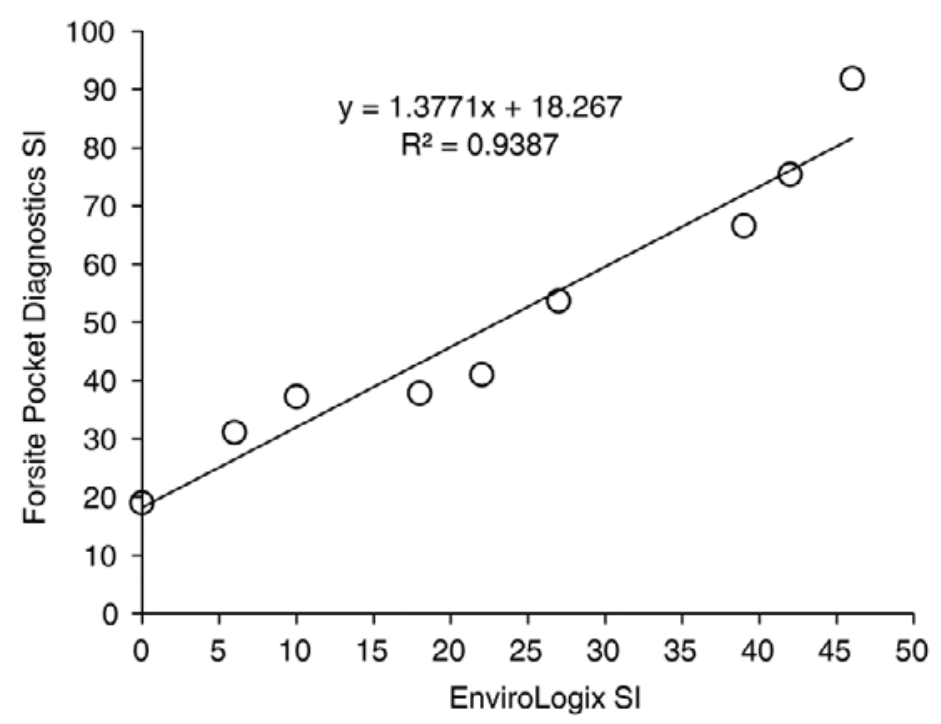

Figure 3 Comparison of the EnviroLogix B-LFDs with the Forsite Pocket Diagnostics B-LFDs (batch U05) for the quantification of Botrytis antigens in a dilution series $(0.0-1 \%)$ of the reference dessert wine, Dolce, in PBST, SI= Signal intensity. 

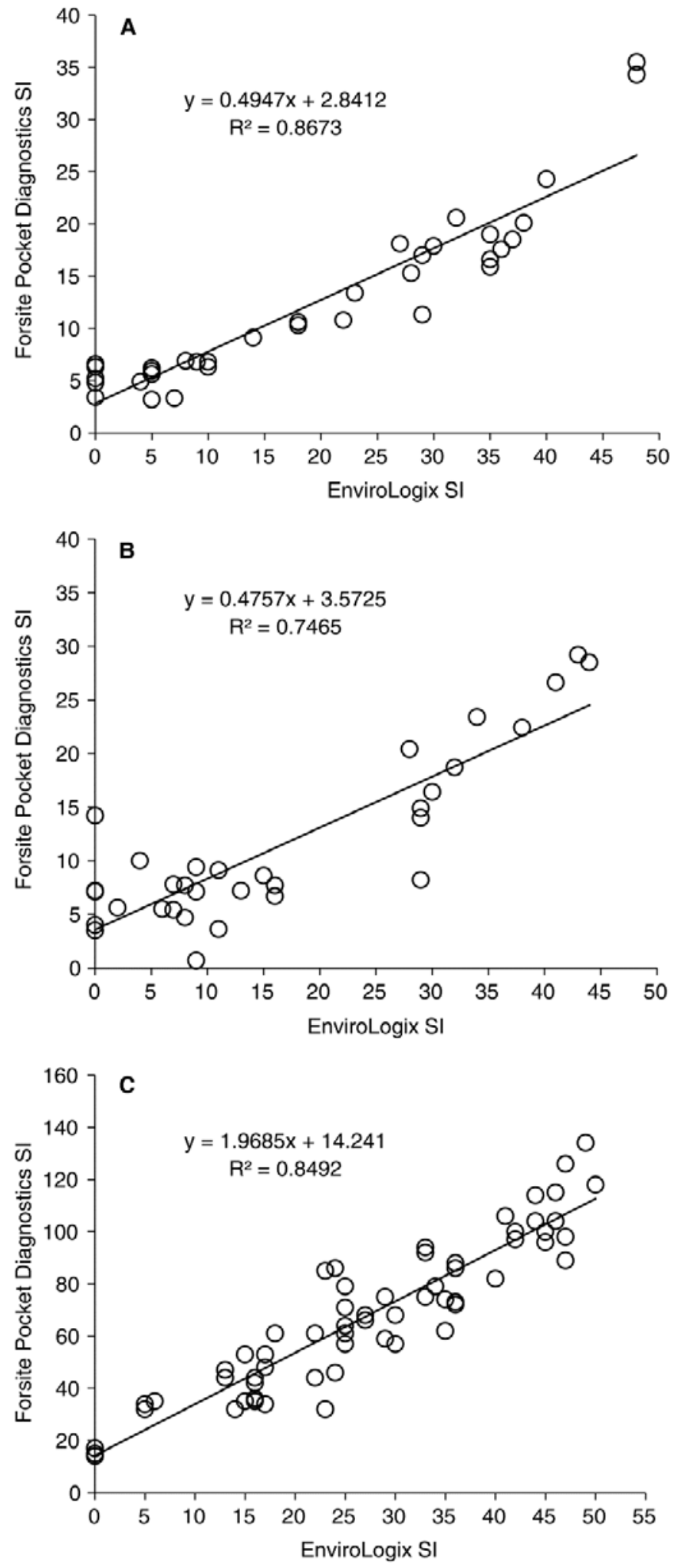

Figure 4 Comparison of the EnviroLogix BLFD with the Forsite Pocket Diagnostics BLFD for the quantification of Botrytis antigens in red wines $(\mathbf{A})$, white wines $(\mathbf{B})$, and a series of dessert wines from Australia and France (C). SI= Signal intensity. 